\title{
Effect of migration, distribution and spacing of pig embryos on pregnancy and fetal survival
}

\author{
P. Dziuk \\ 111 Animal Genetics, University of Illinois, 1301 W. Lorado Taft Drive, Urbana, Illinois 61801, U.S.A.
}

\begin{abstract}
Summary. Pig embryos enter the uterus from the oviduct about $48 \mathrm{~h}$ after ovulation at about the 4-cell stage. They remain near the tip of the uterine horn until about Day 6 when they migrate towards the body of the uterus. By Day 9 some embryos have entered the horn opposite the one of origin and continue migrating until Day 12. At Day 12 embryos can no longer successfully move to a different site. The critical signal for recognition of pregnancy occurs at Day 12 at the same time that embryos are elongating at a rapid rate. The distribution of embryos throughout the length of the horns has occurred by this time and spacing accompanied by uterine growth takes place. The speed of migration is not influenced by the number of embryos but may be affected by secretions from the embryos acting on the uterus. A significant section of unoccupied uterus at Day 12 will prevent continuance of pregnancy regardless of the number of embryos present in the occupied section. When the number of embryos is so few as to not occupy the uterus fully, pregnancy will not continue. Removal of embryos from a significant section of the uterus after Day 14 does not stop an existing pregnancy. Embryos are spaced nearly equidistant from each other with the absolute space between fetuses dependent on the total uterine space available. The position of the fetus in the uterus affects the spacing between fetuses; fetuses at the tip of the horn before Day 25 have the greatest space with the space decreasing from the tip to the body. Due to resorptions near the body, the space per live fetus is greater and roughly equal near the body and the tip from Day 35 and later. Fetuses in the middle of the horn are then most likely to have limited space and be smaller at birth than their litter mates.
\end{abstract}

\section{Introduction}

This paper describes those aspects of the embryo-uterine relationship which emphasize the implications and effects of the location of the embryo within the uterus on pregnancy, without delving deeply into the possible biochemical or neurological mechanisms. Other aspects are no less important and are the subjects of other reviews (Dziuk, 1977; Bazer, Geisert, Thatcher \& Roberts, 1982; Bazer \& First, 1983).

A pig embryo has some of the same problems that we as humans have when we select a place to live. We usually have to move some distance from the point where we originated. We are constantly maturing and have constantly changing requirements. A critical minimum number of us are required to establish viable units. We like to have and need a certain distance separating us from our neighbours; living space as it were. The boundary lines between us and our neighbours are usually quite distinct. We send out to our environment certain signals that indicate our presence and in return receive certain benefits and services. The similarity between us and pig embryos in seeking a place to live is striking but fortunately for us few of our concerns are as truly life-and-death as they are for the pig embryo. 
To facilitate the discussion the subject has been arbitrarily divided into four overlapping areas; migration of embryos, distribution and spacing of embryos, maintenance of pregnancy and fetal growth and survival.

\section{Migration}

Migration of embryos occurs more or less continuously from the time of fertilization, shortly after ovulation, until about Day 12 of gestation (Dhindsa, Dziuk \& Norton, 1967). The embryo is moved to the ampullary-isthmic junction within a few hours of fertilization and remains there for about $36 \mathrm{~h}$. Embryos usually enter the uterus from the oviduct $48 \mathrm{~h}$ after ovulation when they are at the 4-cell stage. The rate of passage through the oviduct may be greatly speeded by administration of progesterone to the female before ovulation (Day \& Polge, 1968). This would indicate that the passage of the embryo through the oviduct is controlled by hormones that influence the oviduct. Oestrogen has been found to trap eggs in the oviduct for periods up to 21 days (C. Polge \& P. Dziuk, unpublished). One may deduce that progesterone allows the embryos to migrate through the isthmus whereas oestrogen tends to restrict movement of embryos through the isthmus. Because concentrations of oestrogen in plasma normally decline after ovulation and values of progesterone increase, the sequence and interrelationship of these hormone concentrations and movement of the embryo seem quite logical. The fact that they seem so logical is reason to be suspicious that it is not nearly so simple.

Once the embryo reaches the uterus, it must migrate from the point of entry at the tip of a uterine horn to perhaps the body of the uterus which may be a journey of $100 \mathrm{~cm}$. Because the embryo has no intrinsic means of movement it is at the mercy of the motility of the uterus for travel. Once started, migration along the length of the horn of origin and then through the uterine body to the opposite horn is a gradual progression (Dhindsa et al., 1967). Initially, embryos remain in the vicinity of the tip of the horn until Day 6, and then progress through the horn during Days 7 and 8. By Day 9 some embryos have usually entered the horn opposite the one of origin and by Day 12 fully occupy both horns. The number of embryos migrating does not seem to influence the rate of passage (Dziuk, Polge \& Rowson, 1964), as more embryos do not migrate faster than fewer embryos. Also, migration does not seem to be a directed process with each embryo designated to go to a specific site, but rather a random movement of embryos with slightly more embryos staying in the horn of origin than migrating to the other horn. Migration through the uterus may be analogous to two groups of round marbles, one group at each end of a long, level, flat-bottomed trough much as a uterus with embryos at each end. If the trough were vibrated for 10 days the marbles from each end would probably be scattered at random throughout the length of the trough but with a tendency to remain at the end of origin. The uterus may simulate this vibration by frequent contractions of relatively low amplitude for the 10 days between Day 3 and Day 12 (Keye, 1923). Embryos can migrate quite readily throughout uterine horns sectioned and reanastomosed in a variety of arrangements (Miller \& Dziuk, 1968). Original anatomical integrity and orientation is not therefore necessary for migration. This would indicate that contractions are not unidirectional but can be peristaltic and antiperistaltic. Evidence that migration is not completely passive and random can be found in experiments using simulated embryos in the form of small polysiloxane capsules either with or without oestradiol incorporated into them (Pope, Maurer \& Stormshak, 1982b). The capsules containing oestradiol migrated more effectively than those with no oestradiol but not so well as would be expected of embryos. This association does not confer a cause and effect relationship on oestradiol as the mediator of migration but it is a lead for further experiments using pseudoembryos that may even more closely simulate the genuine article (Pope et al., 1982a).

During migration, embryos apparently do not repel each other nor do they influence the migration of other embryos. This conclusion is based on two observations. First, when embryos from black parents were transferred to the tip of one uterine horn in a recipient gilt and embryos 
from white parents were placed in the tip of the other horn, fetuses of both colours were found in both horns and were mixed at Day 85 (Dziuk et al., 1964). Position of the fetuses in the uterus was therefore not completely dependent on the horn of origin and in most gilts some of the embryos apparently passed each other in the uterus because fetuses were mixed in a somewhat systematic fashion. Thus as one determines the colour of the fetuses from the tip of the uterine horn of origin and goes progressively through the entire length of both horns of the uterus, one finds that the proportion of the fetuses of the colour of embryos originating in that horn goes from $100 \%$ to zero. Near the body of the uterus, therefore, a fetus is about equally likely to have originated from one ovary as the other but at the tip of the horn it is most probably from the adjacent ovary. The second observation indicating the independence of embryos from each other is the lack of influence of the number of embryos on the rate or distance of migration. This was determined by allowing either the normal number of embryos to originate from one ovary or by doubling the number following ovarian compensation due to removal of the contralateral ovary (Dhindsa et al., 1967). Embryos originating from one ovary with many other embryos migrated at the same rate as those from ovaries producing fewer embryos.

\section{Distribution and spacing}

Although migration may not be influenced by other embryos, distribution and spacing seem to be clearly affected by the proximity of other embryos. The migration of embryos can be restricted by ligating the uterine horn with permanent suture material at specific locations at Day 4 after mating. By counting the corpora lutea on each ovary and ligating at appropriate locations, twice as much uterine space for each potential embryo may be created on one side of the ligature as on the other (Dziuk, 1968). When the uterus was examined at Day 30 or later, fetuses were spaced equidistant from each other on each side of the ligature but the distance between the fetuses on the crowded side of the ligature was just half that on the uncrowded side. However, neither of these conditions affected the proportion of embryos that survived to Day 30 . This would indicate that embryonic survival is not influenced by uterine space before Day 30 . The equidistant spacing betwen embryos, regardiess of the total space available, would indicate that spacing is not entirely passive but that the embryos can exert a repelling effect on each other. However, it is unlikely that one embryo directly and physically moves another because of the delicate structure of the embryo. An embryo could create space around itself by promoting uterine contractility originating from the location of the embryo which would tend to oppose contractility in adjacent portions of the uterus and hence prevent the migration of embryos towards each other. If several embryos in the same uterus were each generating such repelling contractions, embryos would move to a position at the greatest distance from the origin of such contractions, i.e. equidistance between adjacent embryos. Any capacity to affect local uterine activity must occur after intrauterine migration and mixing but before final attachment and this period of spacing must be no more than a few hours near Day 12 as discussed in the following section.

Infrequent but nevertheless significant instances of extremely high numbers of embryos (30-45) have been found at random by the author when examining genital tracts at Days 25-30 of pregnancy (P. J. Dziuk, unpublished observations). The embryos have been nearly equidistant from each other and with relatively less space per embryo than would be usually expected.

A puzzle that has no ready answer lies in the head-tail orientation of fetuses relative to their position in the uterus. In one study, fetuses in the tip of the horns were found to be more likely than fetuses in other positions to be head towards the cervix (Reimers et al., 1973). Whether the embryo originated in the horn of implantation or not did not influence the orientation.

\section{Maintenance of pregnancy}

The distribution of embryos is critical to maintenance of pregnancy. When each uterine horn is 
ligated at Day 4 after mating at a point midway between the tip and the body of the uterus, the embryos are prevented from occupying half of the uterus. Removal of these ligatures at Days 8, 9, 10 or 11 permits the embryos to continue migration and distribution (Polge \& Dziuk, 1970) and pregnancy will ensue. When the ligatures are removed at Day 12 , the embryos rarely occupy the uterus beyond the ligatures and few pregnancies continue. Removal of the ligature at Day 13 yields no pregnancies unless supplementary corpora lutea are induced or progesterone is administered. The proportion of the uterus that is unoccupied is inversely related to the probability that pregnancy will continue (Dhindsa \& Dziuk, 1968b). When one half is unoccupied pregnancy does not continue, when one-quarter is unoccupied, $20-30 \%$ of pregnancies continue, and when one-eighth is unoccupied, $50-60 \%$ of pregnancies may continue. The creation of conditions in which all the embryos come from one ovary as in unilateral oviduct ligation or unilateral ovariectomy provides evidence that embryos do not reach the contralateral horn until Day 9 and therefore half the uterus is unoccupied until Day 9 (Dhindsa et al., 1967). Pregnancy under these conditions occurs as readily as in females with both uterine horns occupied from Day 4 . Therefore, based on occupancy of the uterus, the determination by the mother that pregnancy should continue is not made until after Day 9. However, when embryos are permanently restricted to one horn by ligatures placed near the body of the uterus, pregnancy fails in nearly every case unless supplemental corpora lutea are induced (Christenson \& Day, 1971) or embryonic extracts are infused (Ball \& Day, 1982a, b).

Evidence submitted thus far would indicate that the critical period for a signal for the maintenance of pregnancy is after Day 11 but before Day 13, i.e. Day 12. At Day 12 the embryo is growing and elongating very rapidly (Geisert, Brookbank, Roberts \& Bazer, 1982), developing the ability to produce and metabolize many compounds (Cook \& Hunter, 1978; Davis, Pakrasi \& Dey, 1983; Flint, Saunders \& Ziecik, 1982) and also apparently establishes the space between itself and other embryos and can no longer successfully migrate. Once an embryo has exchanged a signal for the maintenance of pregnancy with its mother the question arises as to how positive and permanent is this signal? One approach to this question has been to remove embryos from a segment of the uterus at Day 14, 20 or 30 and determine whether pregnancy would continue (Dhindsa \& Dziuk, 1968a). Removing embryos from one uterine horn at Days 14 and 20 or later did not disrupt preg. nancy and shows that the effect of the unoccupied uterine segment is minimal or absent after Day 14. Moreover in animals with some embryos removed, the levels of progesterone were similar to those of an unaltered pregnancy. Apparently the decision to continue pregnancy is not made before Day 11, but once made at about Day 12, pregnancy will continue after removal or death of most of the embryos at Day 14 or later. The nature of the signal is still a matter of conjecture but the mere presence of an inanimate object in the uterus is not effective, as various items have been inserted to extend the life of the corpora lutea to no avail (Anderson \& Melampy, 1967). The administration of oestrogen to the mother before Day 14 of the oestrous cycle or pregnancy will cause an extension of the life of the corpora lutea for several weeks and pseudopregnancy may persist for nearly as long as pregnancy (Ford, Magness, Farley \& Van Orden, 1982; Geisert, Thatcher, Roberts \& Bazer, 1982). The embryo itself produces oestrogen at early stages (see Bazer \& Thatcher, 1977) and the level of oestrone sulphate in maternal plasma is positively correlated with the number of embryos from Days 20 to 28 (Horne, Chew, Wiseman \& Dziuk, 1983). Based on these observations it seems logical, therefore, that feto-placental oestrogen or its effects are a signal to maintain the corpora lutea and consequently, pregnancy (Saunders, Edgerton, Kagan, Stahly \& Cromwell, 1983).

The role of prostaglandins in the maintenance of pregnancy or in the regression of the corpora lutea of a non-fertile cycle has been the subject of many studies (Hunter, 1977; Ball \& Day, 1982b). Prostaglandin is ineffective as a luteolysin for corpora lutea less than 14 days of development but is quite effective at later stages and during pregnancy. Measurement of metabolites of prostaglandins in the blood of mated females does not lead to the conclusion that the presence or absence of metabolites is functionally related to pregnancy. The partitioning of prostaglandins to either the uterine lumen in the case of pregnancy or to the uterine venous drainage in nonpregnant animals has been postulated as a determining factor or signal (Bazer \& Thatcher, 1977). 
Because a minimum of about 4 embryos is required at Day 12 to maintain pregnancy it would seem reasonable that each embryo may contribute part of a total signal to maintain the function of the corpora lutea and production of progesterone (Polge, Rowson \& Chang, 1966). If this is so, then it might follow that a small number of embryos would produce a smaller signal with partial function of the corpora lutea and perhaps a lower level of progesterone at stages later than Day 14. This surmise turned out to be incorrect (Webel, Reimers \& Dziuk, 1975). A greater number of fetuses did not cause an increase in the concentration of plasma progesterone above that in females with fewer fetuses. Apparently there is a qualitative rather than quantitative signal from the embryos to maintain progesterone production and once the female is pregnant the concentration of progesterone is unaffected by the number of fetuses. This line of inquiry was carried to the extreme in this same study by killing all embryos at Day 30. The progesterone value in these formerly pregnant females did not decline significantly and the corpora lutea continued to function for several weeks. Therefore, once pregnancy is established it will continue for some time even without fetuses, in a form of pseudopregnancy. To continue this reasoning from another aspect, the question was asked, to what extent do the number of corpora lutea, and therefore indirectly the potential number of embryos, influence the level of progesterone? There was good evidence that reducing the number of corpora lutea to 5 or less by unilateral ovariectomy resulted in abortion in $24-48 \mathrm{~h}$ (Martin, BeVier \& Dziuk, 1977) and it therefore seemed that the number of corpora lutea had an important effect on the tevel of progesterone. This turned out to be only partly true during early pregnancy and only when a very low number of corpora lutea was present. By careful stepwise reduction of the number of corpora lutea, pregnancy could be maintained with as few as one corpus luteum (Thomford, Sander, Kendall, Sherwood \& Dziuk, 1984). The concentration of progesterone is somehow regulated so that the level of progesterone in plasma can be the equivalent of from $1 \mathrm{ng} / \mathrm{ml}$ per corpus luteum to as much as $9 \mathrm{ng} / \mathrm{ml}$ per corpus luteum and to some extent is inversely related to the number of corpora lutea. Neither the embryo nor the corpus luteum has a clear quantitative effect on the other when the number of each is within the usual range.

\section{Growth and survival}

The prenatal growth and survival of fetuses is influenced markedly by the spacing and migration of embryos (Webel \& Dziuk, 1974; Anderson \& Parker, 1976). If no intrauterine migration occurred all embryos would implant at one spot at the tip of the horn and few if any would survive. If distribution and spacing were perfect then each fetus would be exactly the same distance from the neighbouring fetuses. This is unrealistic because attachment takes place at Day 12 and some embryos possibly die between Day 13 and Day 40, leaving gaps between fetuses which cannot be easily reoccupied. The embryos and fetuses have a direct effect on the length of the uterus by causing it to elongate and grow locally before Day 30 (Knight, Bazer, Thatcher, Franke \& Wallace, 1977). When each uterine horn of a pregnant gilt is considered separately, the length is directly proportional to the number of fetuses in that horn but is not influenced by the number in the opposite horn (M. Hentzel, M. C. Wu \& P. J. Dziuk, unpublished observations). Growth of the fetus can then be limited when embryos disproportionately occupy one horn. Based on the observation that each fetus causes about $10 \mathrm{~cm}$ of growth (M. Hentzel, M. C. Wu \& P. J. Dziuk, unpublished observations) and assuming a length of a uterine horn to be $70 \mathrm{~cm}$ at Day 10 , then at Day 40 the horn would be $70+(7 \times 10)$ or $140 \mathrm{~cm}$ long when occupied by 7 fetuses. Because each fetus can grow and survive adequately in $20 \mathrm{~cm}$ of space $(140 \mathrm{~cm} / 7$ fetuses) there is no problem if distribution is uniform. However, if 9 fetuses occupy the horn it will only increase to $70 \mathrm{~cm}+90 \mathrm{~cm}$, or $160 \mathrm{~cm}$ in length. The space available to each fetus then is $160 \mathrm{~cm} / 9$ fetuses or $17 \mathrm{~cm}$ per fetus, which is below the $20 \mathrm{~cm}$ level for adequate growth. If embryos were not spaced perfectly equidistant the matter would be even worse. When the number of fetuses per horn is 5 or less the horn does not appear to elongate between Day 35 and Day 100 whereas with 8 fetuses per horn there is some increase in the length of the uterus after Day 35. 
Distribution and spacing does not appear to be uniform throughout the length of the uterus. On the basis of an analysis of measurements in 400 pregnant pigs of the uterine space available to each fetus, fetal length and weight and the proportion of fetuses surviving, the following generalities can be made (M. Hentzel, M. C. Wu \& P. J. Dziuk, unpublished observations). At Day 25 the space available to each fetus decreased in each uterine position as one measured first the space available to the fetuses at the tip of the uterus and went progressively to the body of the uterus. At Day 40 the situation has changed slightly in that the greatest space available to each fetus is now about equally at the tip of the horn and at the body end but least in the middle of each horn. This seems to result from the death and partial resorption of embryos at the formerly crowded body end. Before Days 25 to 30 , uterine space available to each embryo has little influence on embryo survival. This was determined experimentally by transferring 12 or 24 embryos to the uterus and determining the proportion surviving (Pope, Christenson, Zimmerman-Pope \& Day, 1972). In spite of much less uterine space available to each embryo, the recipients with 24 embryos had the same proportion of embryos surviving as did gilts receiving the lesser number. In another experiment (Dziuk, 1968) one uterine horn was ligated at Day 4 to create crowded and uncrowded conditions on either side of the ligature. The survival of embryos was equal under both conditions at least up to Days 25-30, but by Day 70 few fetuses survived in the crowded segment. Studies of pregnant gilts with one horn and one ovary also indicate that embryos can survive to at least Day 28 with very restricted space (Dziuk, 1968). However, each fetus needs about $20 \mathrm{~cm}$ of uterine length to survive (Knight et al., 1977). As each fetus causes the uterus to grow about $10 \mathrm{~cm}$ between Day 10 and Day 30 , an embryo that has less than $10 \mathrm{~cm}$ of space available at Day 10 is destined to have less than the required $20 \mathrm{~cm}$ at Day 30 and these fetuses may die and be resorbed prenatally or will be smaller than their littermates and born as runts. In contrast, when embryos have more than $25-30 \mathrm{~cm}$ of space they are not heavier than their littermates as a consequence of this additional space.

Very uniform distribution of embryos with each occupying $20 \mathrm{~cm}$ of space, no more or no less, would therefore optimize litter size, fetal growth and survival. It is imperative to each embryo that migration, spacing and distribution be equitable very early in gestation because the consequences are life-and-death.

The data reviewed in this paper represent the diligent studies of a number of graduate students working in the author's laboratory over a period of time.

\section{References}

Anderson, L.L. \& Melampy, R.M. (1967) Hypophysial and uterine influence on pig luteal function. In Reproduction in the Female Mammal, pp. 285-316. Eds G. E. Lamming \& E. C. Amoroso. Butterworths, London.

Anderson, L.L. \& Parker, R.O. (1976) Distribution and development of embryos in the pig. J. Reprod. Fert. 46, 363-368.

Ball, G.D. \& Day, B.N. (1982a) Bilateral luteal maintenance in unilaterally pregnant pigs with infusions of embryonic extract. J. Anim. Sci. 54, 142-149.

Ball, G.D. \& Day, B.N. (1982b) Local effects of PGF 2 and embryonic extracts on luteal function in swine. $J$. Anim. Sci. 54, 150-154.

Bazer, F.W. \& First, N.L. (1983) Pregnancy and parturition. J. Anim. Sci. 57, Suppl. 2, 425-460.

Bazer, F.W. \& Thatcher, W.W. (1977) Theory of the maternal recognition of pregnancy in swine based on estrogen controlled endocrine versus exocrine secretion of prostaglandin $\mathrm{F}_{2} \mathrm{a}$ by the uterine endometrium. Prostaglandins 14, 397-401.
Bazer, F.W., Geisert, R.D., Thatcher, W.W. \& Roberts, R.M. (1982) The establishment and maintenance of pregnancy. In Control of Pig Production, pp. 227-252. Eds D. J. A. Cole \& G. R. Foxcroft. Butterworths, London.

Christenson, R.K. \& Day, B.N. (1971) Maintenance of unilateral pregnancy with induced corpora lutea. $J$. Anim. Sci. 32, 282-286.

Cook, B. \& Hunter, R.H.F. (1978) Systemic and local hormonal requirements for implantation in domestic animals. J. Reprod. Fert. 54, 471-482.

Davis, D.L., Pakrasi, P.L. \& Dey, S.K. (1983) Prostaglandins in swine blastocysts. Biol. Reprod. 28, $1114-1118$.

Day, B.N. \& Polge, C. (1968) Effects of progesterone on fertilization and egg transport in the pig. J. Reprod. Fert. 17, 227-230.

Dhindsa, D.S. \& Dziuk, P.J. (1968a) The effect of pregnancy in the pig after removal of embryos from one uterine horn in early gestation. J. Anim. Sci. 27, $122-126$. 
Dhindsa, D.S. \& Dziuk, P.J. (1968b) Influence of varying the proportion of uterus occupied by embryos on maintenance of pregnancy in the pig. J. Anim. Sci. 27, 668-672.

Dhindsa, D.S., Dziuk, P.J. \& Norton, H.W. (1967) Time of transuterine migration and distribution of embryos in the pig. Anat. Rec. 159, 325-330.

Dziuk, P.J. (1968) Effect of number of cmbryos and uterine space on embryo survival in the pig. J. Anim. Sci. 27, 673-676.

Dziuk, P.J. (1977) Reproduction in pigs. In Reproduction in Domestic Animals, pp. 445-474. Eds H. H. Cole \& P. T. Cupps. Academic Press, New York.

Dziuk, P.J., Polge, C. \& Rowson, L.E. (1964) Intrauterine migration and mixing of embryos in swine following egg transfer. J. Anim. Sci. 23, 37-42.

Flint, A.P.F., Saunders, P.T.K. \& Ziecik, A.J. (1982) Blastocyst-endometrium interactions and their significance in embryonic mortality. In Control of Pig Reproduction, pp. 253-276. Eds D. J. A. Cole \& G. R. Foxcroft. Butterworths, London.

Ford, S.P., Magness, R.R., Farley, D.B. \& Van Orden, D.E. (1982) Local and systemic effects of intrauterine estradiol-17 $\beta$ on luteal function of nonpregnant sows. J. Anim. Sci. 55, 657-664.

Geisert, R.D., Brookbank, J.W., Roberts, R.M. \& Bazer, F.W. (1982) Establishment of pregnancy in the pig. I1. Cellular remodeling of the porcine blastocyst during elongation on day 12 of pregnancy. Biol. Reprod. 27, 941-955.

Geisert, R.D., Thatcher, W.W., Roberts, R.M. \& Bazer, F.W. (1982) Establishment of pregnancy in the pig III. Endometrial secretory response to estradiol valerate administered on day 11 of the estrous cycle. Biol. Reprod. 27, 957-965.

Horne, C., Chew, B.P., Wiseman, B.S. \& Dziuk, P. J. (1983) Relationship between the level of estrone sulfate in the plasma and number of fetuses during pregnancy in the gilt. Biol. Reprod. 29, 56-62.

Hunter, R.H.F. (1977) Physiological factors influencing ovulation, fertilization and early embryonic development and establishment of pregnancy in pigs. Br. vet. J. 133, 461-470.

Keye, J.D. (1923) Periodic variation in spontaneous contraction in uterine muscle in relation to the estrous cycle and early pregnancy. Bull. Johns Hopkins Hosp. 34, 60-63.

Knight, J.W., Bazer, F.W., Thatcher, W.W., Franke, D.E. \& Wallace, H.D. (1977) Conceptus development in intact and unilaterally hysterectomized-ovariectomized gilts: Interrelationship among hormonal status, pla- cental development, fetal fluids and fetal growth. $J$. Anim. Sci. 44, 620-637.

Martin, P.A., BeVier, G.W. \& Dziuk, P.J. (1977) The effect of number of corpora lutea on the length of gestation in pigs. Biol. Reprod. 16, 633-637.

Miller, O.C. \& Dziuk, P.J. (1968) Migration of embryos in the anastomosed uterine horns of the pig. Anat. Rec. 162, 137-138.

Polge, C. \& Dziuk, P.J. (1970) Time of cessation of intrauterine migration of pig embryos. J. Anim. Sci. 31, 565-566.

Polge, C., Rowson, L.E.A. \& Chang, M.C. (1966) The effect of reducing the number of embryos during early stages of gestation on the maintenance of pregnancy in the pig. J. Reprod. Fert. 12, 395-397.

Pope, C.E., Christenson, R.K., Zimmerman-Pope, V.A. \& Day, B.N. (1972) Effect of number of embryos on embryonic survival in recipient gilts. J. Anim. Sci. 35, 805-808.

Pope, W.F., Maurer, R.R. \& Stormshak, F. (1982a) Intrauterine migration of the porcine embryo. Interaction of embryo, uterine flushings and indomethacin on myometrial function in vitro. $J$. Anim. Sci. 55, 1169-1178.

Pope, W.F., Maurer, R.R. \& Stormshak, F. (1982b) Intrauterine migration of the porcine embryo: influence of estradiol-17及 and histamine. Biol. Reprod. 27, 575-579.

Reimers, T.J., Dziuk, P.J., Bahr, J., Sprecher, D.J., Webel, S.K. \& Harmon, B.G. (1973) Transuterine embryonal migration in sheep, anteroposterior orientation of pig and sheep fetuses and presentation of piglets at birth. J. Anim. Sci. 37, 1212-1217.

Saunders, M.J., Edgerton, L.A., Kagan, J.M., Stahly, T.S.. \& Cromwell, G.L. (1983) Comparison of intrauterine and subcutaneous sites of estrogen injection for luteal maintenance in swine. J. Anim. Sci. 57, 146-149.

Thomford, P.J., Sander, H.K.L., Kendall, J.Z., Sherwood, O.D. \& Dziuk, P.J. (1984) Maintenance of pregnancy and levels of progesterone and relaxin in the serum of gilts following a stepwise reduction in the number of corpora lutea. Biol. Reprod. 31, 494-498.

Webel, S.K. \& Dziuk, P.J. (1974) Effect of stage of gestation and uterine space on prenatal survival in the pig. J. Anim. Sci. 38, 960-963.

Webel, S.K., Reimers, T.J. \& Dziuk, P.J. (1975) The lack of relationship between plasma progesterone levels and number of embryos and their survival in the pig. Biol. Reprod. 13, 177-186. 